\title{
A STUDY OF PREDICTORS OF SAM IN CHILDREN OF NRC OF GUNTUR MEDICAL COLLEGE
}

P. Sudha Kumari ${ }^{1}$

\section{HOW TO CITE THIS ARTICLE:}

P. Sudha Kumari. "A Study of Predictors of SAM in Children of NRC of Guntur Medical College, Guntur". Journal of Evolution of Medical and Dental Sciences 2015; Vol. 4, Issue 03 January 08; Page: 393-399,

DOI: $10.14260 /$ jemds $/ 2015 / 60$

\begin{abstract}
The incidence of Malnutrition and Severe Acute malnutrition is very high in India leading to higher Infant mortality rate and Under 5 mortality rates which has to be studied in depth in relation to various risk factors. OBJECTIVE: To study the Risk factors of Severe Acute Malnutrition in the children admitted in the Nutritional Rehabilitation Centre. MATERIALS \& METHODS: A hospital based cross sectional study was conducted. A total of 164 SAM children admitted in Nutritional rehabilitation centre, Guntur medical college, Guntur, over a period of 6 months constituted the study population. Various risk factors that are having influence on the child which leads to SAM were studied. The data was analyzed by using excel and depicted in proportions and cross tabulations. The significance was tested by Chi-square test. RESULTS: Place of residence, Fathers education, Socio economic status, LBW/Pre term babies, Recurrent Respiratoty Infections, Recurrent Diarrheoa, and other morbid conditions, were the various risk factors that lead to the development of SAM in the study subjects. CONCLUSIONS: The results of the present study revealed various risk factors combindly were attributed to the higher incidence of SAM cases which may be reduced by quality antenatal, intra natal and neonatal care and improvement of infant and young child feeding practices and early and proper medical treatment of the morbid conditions.
\end{abstract}

KEYWORDS: Predictors, SAM children, Malnutrition, GMC, Guntur.

INTRODUCTION: Severe acute malnutrition (SAM) is a major public health issue. It afflicts an estimated 8.1 million under-five children in India causing nearly 0.6 million deaths. The improved understanding of pathophysiology of SAM as well as new internationally accepted growth charts and newer modalities of integrated intervention have necessitated a relook at IAP recommendations. ${ }^{1}$

Malnutrition in India is a major public health problem. The NFHS-3 revealed that $6.4 \%$ of all children under five years of age are severely wasted. Children with Severe Acute Malnutrition (SAM) have 9 times higher risk of dying than well-nourished children. With appropriate nutritional and clinical management, many of the deaths due to severe wasting can be prevented. ${ }^{2}$

NFHS 3 shows that the proportion of children who are stunted or underweight increases rapidly with the child's age from birth to age 20- 23 months peaking at age 20 months. ${ }^{2}$

Severe Acute Malnutrition (SAM) is defined by very low weight for height/length (Z score below -3 SD of the median WHO child growth standards), a mid-upper arm circumference $<115 \mathrm{~mm}$, or by the presence of nutritional oedema. ${ }^{2}$

\section{Diagnostic criteria for SAM in children aged 6-60 months. ${ }^{2}$}

- Severe wasting- Wt for $\mathrm{Ht}<-3 \mathrm{SD}$,

- Severe wasting- MUAC $<115 \mathrm{~mm}$.

- Bilateral Oedema Clinical sign Reference: WHO/UNICEF Joint Statement. 


\section{ORIGINAL ARTICLE}

Under NRHM NRCs have been set up at health facilities in Andhra Pradesh which focus on the facility based approach for the management of SAM children, while recognizing the need for an integrated community care of children with SAM.

The updated WHO guidelines recommend that children with severe acute mal nutrition who do not have health complications that require hospitalization receive special high energy food and antibiotics to treat infection. This allows them to recover at home with their families. They also give guidance on how to treat them for HIV and if necessary make recommendations on how to treat severely malnourished infants under 6 months. The guidelines are critical because many national health plans currently over look children with severe acute malnutrition. If these, children don't get the right medical and nutritional care, very often they die. Dr Francesco Banca, Director, WHO, Department of Nutrition for Health and Development. ${ }^{3}$ The guidelines have been updated to reflect new opportunities and technologies that allow severely malnourished children who have an appetite and no evident medical complications to be effectively treated at home with specially-formulated foods that provide energy and nutrients and antibiotic medicines. ${ }^{3}$

An integrated management of malnutrition is likely to yield more dividends. Thus, management of SAM should constitute an important component of Integrated Management of Neonatal and Childhood Illnesses (IMNCI) program. Determination of SAM on the basis of Z-scores using WHO Growth charts is considered statistically more appropriate than cut-offs based on percentage weight deficit of the median. Considering the fact that many children with SAM can be successfully managed on outpatient basis and even in the community, it is no more considered necessary to advise admission of all children with SAM to a healthcare facility. Management of SAM should not be a stand-alone program. It should integrate with community management therapeutic programs and linkages with child treatment center, district hospitals and tertiary level centers offering inpatient management for SAM and include judicious use of ready-to-use-therapeutic Food (RUTF). All sections of healthcare providers need to be trained in the integrated management of SAM. ${ }^{1}$

SCREENING FOR SAM IN THE COMMUNITY: Active and early case finding is an important determinant of case fatality rate, programme coverage and the programme impact. To reduce the barriers to access, reduce case fatality and improve programme impact, screening must take place in the community and before the onset of medical complications. Front line community workers (AWW, ASHA, ANM) can identify children with SAM by using simple coloured plastic strips that are designed to measure mid upper arm circumference (MUAC). They should also be able to recognise nutritional oedema of the feet, which is another sign of this condition. Once identified, these children with SAM need further assessment to determine if they require referral to health facility and facility based care or whether they can be managed at community level with visits as out-patients to a health Centre or facility. ${ }^{2}$

OBJECTIVE OF THE STUDY: To know the various risk factors of SAM children admitted in the Nutritional Rehabilitation Centre of GMC, Guntur.

MATERIALS \& METHODS: A hospital based cross sectional study was conducted. 164 SAM children were covered over a period of 6 months. All the admitted SAM children during the months of April to 


\section{ORIGINAL ARTICLE}

September were selected. Study setting: This study was conducted in the Nutritional Rehabilitation Centre of Guntur Medical College, Guntur, which is a teaching hospital where majority of patients were referred from all over the periphery, other districts and private clinics. NRC is the place where children having Severe Acute Malnutrition were admitted, treated and rehabilitated. The mothers of SAM children were interviewed according to pre designed and pretested questionnaire. All the mothers of SAM children were informed about the purpose of the study in the language they could understand and consent was taken from them. Study tools were pre tested. The questionnaire included various risk factors like demographic characters, literacy, income, birth order, access to health care services, birth weight, infant \& young child feeding practices, health problems that are having influence on the child which leads to SAM.

ETHICAL APPROVAL: Research protocol was approved by institutional ethical review committee of Guntur Medical College, Guntur.

ANALYSIS: Data was entered in to an excel spread sheet and double checked for errors. Data was analyzed by using Epi info and depicted in proportions and cross tabulations. Chi-square test was applied to test the relationship of categorized independent and dependent variables. A P value (Significance) of $<0.05$ was deemed statistically significant.

RESULTS: From Table 1 The percentage of SAM children were found to be more in the Rural area (64\%) than urban (36\%). 62\% of the mothers were having only Primary education and 55.48\% of fathers were also having primary education only. $79.88 \%$ of the SAM children belongs to Below poverty line. $65.24 \%$ of the mothers of SAM children were having BMI less than eighteen years. $58.54 \%$ of children have born with LBW/Pre term. Majority of SAM children $(72.56 \%)$ were having Recurrent Respiratory infections, Recurrent diarrhea or other Morbid conditions.

From Table 2 The model shows that Rural place of residence, fathers education, Low socio economic status, LBW/Pre term birth of the babies, Recurrent respiratory infections, Recurrent diarrhea and other Morbid conditions were most significant risk factors in the SAM children admitted in NRC, Guntur Medical college.

In a similar study by A. Basit, S. Nair, KB Chakraborthy. BB Darshan. A Kamath, Under nutrition was associated with illness in the last one month, feeding diluted milk and having more than 2 children with a birth interval less than 2 years. ${ }^{4}$

In a study by Talbert A 1 , et al Diarrhoea complicating severe acute malnutrition in Kenyan children: a prospective descriptive study of risk factors and outcome, Children with SAM complicated by diarrhea had a higher risk of death than those who did not have diarroea during their hospital stay. Further operational and clinical research is needed to reduce mortality in children with SAM in the given setting. ${ }^{5}$

Mishra K 1, Kumar P, et al, in their study on Risk factors for Severe acute mal nutrition in children below $5 \mathrm{y}$ of age in India. Multivariate analysis revealed that the risk of SAM was independently associated with 6 risk factors, namely, illiteracy among mothers, incomplete immunization, practice of bottle feeding, consistency of complementary feeding, deprivation of colostrum and receipt of pre- lacteals at birth. ${ }^{6}$ 


\section{ORIGINAL ARTICLE}

In another study by Ricci J.A. et al, results support biological and epidemiologic evidence that wasting and stunting represent different processes of malnutrition. They also indicate that the principal risk factors for stunting and wasting in infants $<6$ mo of age were either maternal behaviors or child biological characteristics under maternal control, eg, breast-feeding status and birth weight. After 6 mo of age, household socioeconomic characteristics emerged with behavioral and biological variables as important determinants of malnutrition, eg, father's education and presence of a television and/or radio. Household socioeconomic status influenced the risk of stunting earlier in rural than in urban barangays. ${ }^{7}$

DISCUSSION AND CONCLUSION: Place of residence i.e. Rural residence, Fathers education, Socio economic status, LBW/Pre term birth of the babies, Recurrent respiratoty infections, Recurrent diarrheoa, and other morbid conditions, were the major risk factors that lead to the development of SAM in our study. Proper Antenatal, Intra natal and post natal care should be provided for the mother to reduce the Pre term and Low birth weight babies. Proper education of the rural poor mothers and fathers regarding good young child feeding practices and child care and educate them for proper health seeking behavior when the baby is sick.

The Consensus statement of the Indian Academy of Paediatrics on Integrated Management of Severe Acute Malnutrition. By Samir Dalwai et al, has stated that, An integrated management of malnutrition is likely to yield more dividends. Management of SAM should constitute an important component of IMNCI program. Determination of Z Scores using WHO growth charts is considered statistically more appropriate than cut offs based on percentage weight deficit of the median. ${ }^{1}$

It is no more considered necessary to advice admission of all children with SAM to a health care facility. Management of SAM should not be a standalone program. It should integrate with community management therapeutic programs and linkages with child treatment center, district hospitals and tertiary level centers offering in patient management for SAM and include judicious use of ready to use therapeutic food. All sections of health care providers need to be trained in the Integrated management of SAM. ${ }^{8}$

ACKNOWLEDGEMENTS: Author acknowledge the immense help received from the scholars whose articles are cited and included in references of this manuscript. The author is grateful to authors/editors/publishers of all those articles, journals and books from where the literature for this article has been reviewed and discussed.

\section{REFERENCES:}

1. Dalwai S, Choudhury P, Bavdekar SB, Dalal R, Kapil U, Dubey AP, Ugra D, Agnani M, Sachdev HP; Consensus Statement of the Indian Academy of Pediatrics on integrated management of severe acute malnutrition. Indian Pediatr. 2013 Apr; 50 (4): 399-404.

2. Operational guidelines on Facility Based Management of children with SAM, Ministry of Health and Family Welfare, Govt of India, 2011.

3. WHO issues new guidance for treating children with Severe Acute Malnutrition - note for media. 27 November 2013/Geneva.

4. A. Basit, S. Nair, KB Chakraborthy. BB Darshan. A Kamath, Australasian Medical Journal 2012; 5 (3): 163-167. Published online Mar 31, 2012. Doi: 10.4066/AMJ.20121022. 


\section{ORIGINAL ARTICLE}

5. Talbert A 1, et al Diarrhoea complicating severe acute malnutrition in Kenyan children: a prospective descriptive study of risk factors and outcome. PloS One. 2012; 7 (6): e38321. doi: 10.1371/journal.pone.0038321.Epub 2012 Jun 4.

6. Mishra K 1, Kumar P, et al, Risk factors for Severe acute mal nutrition in children below 5 y of age in India: A case- control study. Indian J Paediatr, 2014 Aug; 81(8):762-5. Doi: 10.1007/s 12098-013-1127-3. Epub 2013 Jul 20.

7. Ricci JA ${ }^{1}$, Becker S. Risk factors for wasting and stunting among children in Metro Cebu, Philippines. Am J Clin Nutr. 1996 Jun; 63 (6): 966-75.

8. Samir Dalwai et al, Consensus statement of the Indian Academy of Paediatrics on Integrated Management of Severe Acute Malnutrition. Indian Paediatr (2013), 50; 399- 404.

\begin{tabular}{|c|c|c|}
\hline Characteristics & N (\%) & Mean \pm Sd \\
\hline \multicolumn{3}{|l|}{ Place of residence } \\
\hline Rural & $105(64)$ & \\
\hline Urban & $59(36)$ & \\
\hline \multicolumn{3}{|l|}{ Mothers education } \\
\hline Illiterate & $10(6.09)$ & \\
\hline Primary & $102(62.19)$ & \\
\hline Secondary & $43(26.2)$ & \\
\hline Higher & $9(5.48)$ & \\
\hline \multicolumn{3}{|l|}{ Fathers education } \\
\hline Illiterate & $4(2.44)$ & \\
\hline Primary & $91(55.48)$ & \\
\hline Secondary & $49(29.88)$ & \\
\hline Higher & $10(6.09)$ & \\
\hline \multicolumn{3}{|l|}{ Socioeconomic status } \\
\hline BPL & $131(79.88)$ & \\
\hline APL & $33(20.12)$ & \\
\hline \multicolumn{3}{|l|}{ Children age(months) } \\
\hline $0-11$ & $26(15.85)$ & \\
\hline $12-23$ & $51(31.09)$ & \\
\hline $24-35$ & $43(26.2)$ & $25.86 \pm 18.46$ \\
\hline $36-47$ & $23(14.02)$ & \\
\hline $48-59$ & $21(12.8)$ & \\
\hline \multicolumn{3}{|l|}{ Mothers BMI } \\
\hline$<18$ & $107(65.24)$ & $1005+207$ \\
\hline$>=18$ & $57(34.76)$ & $19.00 \pm 3.92$ \\
\hline \multicolumn{3}{|l|}{ Bottle feeding } \\
\hline Yes & $26(15.87)$ & \\
\hline No & $138(84.13)$ & \\
\hline \multicolumn{3}{|l|}{ LBW/Preterm labour } \\
\hline Yes & $68(41.46)$ & \\
\hline No & $96(58.54)$ & \\
\hline
\end{tabular}




\section{ORIGINAL ARTICLE}

\begin{tabular}{|c|c|}
\hline $\begin{array}{r}\text { Prolonged breast feeding } \\
\text { Yes } \\
\text { No }\end{array}$ & $\begin{array}{c}118(71.95) \\
46(28.05)\end{array}$ \\
\hline $\begin{array}{c}\text { Recurrent respiratory infections/ } \\
\text { Recurrent diarrhea/ Other morbid conditions } \\
\text { Yes } \\
\text { No }\end{array}$ & $\begin{array}{c}119(72.56) \\
45(27.44)\end{array}$ \\
\hline
\end{tabular}

\begin{tabular}{|c|c|c|}
\hline Characteristics & SAM & P VALUE \\
\hline \multicolumn{3}{|l|}{ Place of residence } \\
\hline Rural & $0.69(0.54-1.02)$ & 0.012 \\
\hline Urban & $1.02(0.89-1.59)$ & 0.459 \\
\hline \multicolumn{3}{|l|}{ Fathers education } \\
\hline Illiterate & $2.34(1.36-2.85)$ & 0.003 \\
\hline Primary & $2.12(1.23-2.26)$ & 0.032 \\
\hline Secondary & $1.56(1.12-2.12)$ & 0.013 \\
\hline Higher & $1.07(0.56-1.57)$ & 0.532 \\
\hline \multicolumn{3}{|l|}{ Socioeconomic status } \\
\hline BPL & $4.34(2.56-6.54)$ & 0.02 \\
\hline APL & $1.92(1.45-3.45)$ & 0.044 \\
\hline \multicolumn{3}{|l|}{ LBW/Preterm labour } \\
\hline Yes & $4.85(2.47-5.89)$ & 0.005 \\
\hline No & $1.04(0.67-0.97)$ & 0.642 \\
\hline \multicolumn{3}{|l|}{$\begin{array}{l}\text { Recurrent respiratory infections/ } \\
\text { Recurrent diarrhea/ Other morbid conditions }\end{array}$} \\
\hline Yes & $3.45(2.45-5.34)$ & 0.000 \\
\hline No & $1.08(0.34-0.94)$ & 0.234 \\
\hline
\end{tabular}

$\mathrm{P}<0.05$, considered as statistically significant. 


\section{ORIGINAL ARTICLE}

\section{AUTHORS:}

1. P. Sudha Kumari

\section{PARTICULARS OF CONTRIBUTORS:}

1. Associate Professor, Department of Community Medicine, Guntur Medical College, Guntur.

\section{NAME ADDRESS EMAIL ID OF THE}

\section{CORRESPONDING AUTHOR:}

Dr. P. Sudha Kumari,

Dept. of Community Medicine, Guntur Medical College, Guntur.

E-mail: drpsudha@yahoo.co.uk

Date of Submission: 03/01/2015.

Date of Peer Review: 03/01/2015.

Date of Acceptance: 05/01/2015.

Date of Publishing: 06/01/2015. 